\title{
Psychiatric Re-Hospitalization and Symptom Relapse as a Function of Problem Solving Skills
}

\author{
David Miller¹, Rachel Detrie², Danielle Paull², and George Ronan², \\ ${ }^{1}$ Private Practice, United States \\ ${ }^{2}$ Central Michigan University, Mt Pleasant, MI 48859, United States
}

*Corresponding author: George Ronan, Central Michigan University, Mt Pleasant, MI 48859, United States, Tel: 9896218994; E-mail: ronan1gf@ cmich.edu

Received: 27 Apr, 2020 | Accepted: 14 May, 2020 | Published: 22 May, 2020

Citation: Miller D, Detrie R, Paull D, Ronan G (2020) Psychiatric Re-Hospitalization and Symptom Relapse as a Function of Problem Solving Skills. J Psychiatry Ment Health 5(1): dx.doi.org/10.16966/2474-7769.136

Copyright: (c) 2020 Miller D, et al. This is an open-access article distributed under the terms of the Creative Commons Attribution License, which permits unrestricted use, distribution, and reproduction in any medium, provided the original author and source are credited.

\begin{abstract}
Psychiatric hospitalization is costly for patients who suffer from chronic mental illness, and many hospitalized psychiatric patients are re-hospitalized within a year of discharge. In addition to financial strain, this "revolving door" phenomenon can also have a negative impact on social adjustment. This study explored whether personal problem solving skills assessed at discharge can predict the likelihood of re-hospitalization. Two hundred and four patients recruited from 3 rural psychiatric hospitals participated in this study on hospitalization. Just prior to discharge, participants completed measures of life stress, symptom severity, and both a self-report and a performance based measure of social problem solving. Follow up at 3 and 6 months post discharge evaluated psychiatric symptoms and rates of re-hospitalization. After controlling for relevant predictor variables, the performance based measure of social problem predicted re-hospitalization at 3 months, whereas self-reported problem solving predicted selfreported psychiatric symptoms at 3 and 6 months.
\end{abstract}

Keywords: Psychiatric Hospitalization; Readmission; Re-hospitalization; Revolving door phenomenon; Problem-Solving; Psychiatric relapse

\section{Introduction}

Despite advances in psychotropic and psychologically based outpatient treatments for chronic mental illness, acute hospitalization can be necessary for the provision of a safe therapeutic environment and the reduction of harmful behaviors. Mental illness is the third most common cause of hospitalizations for those aged 18-44 in the United States, with 4.8 million individuals visiting the emergency department for mental disorders as a primary diagnosis (Center for Disease Control and Prevention, 2017). The Agency for Healthcare Research and Quality reported that approximately 2.1 million individuals were hospitalized for mental health concerns, which is a $20.1 \%$ increase since 2005. Of these individuals, the most treated diagnoses were mood disorder, followed by schizophrenia and psychotic disorders [1]. Despite this increase in psychiatric hospitalization, less money was spent for these hospital stays while in every other category of hospitalizations spending increased [2].

Patients with a history of psychiatric admissions are at a continued risk for subsequent psychiatric hospitalization [3]. Haywood TW, et al. [4] coined this phenomenon as the "revolving door" problem. Zhao and colleagues [5] reported that $23 \%$ reported re-hospitalization within three to months of their original visit [5]. Of this sample, 33\% of patients had a diagnosis of schizophrenia/unspecified psychosis, $31.4 \%$ had a diagnosis of bipolar disorder, and $17.9 \%$ had a diagnosis of major depressive disorder. The study also confirmed previous findings that the number of psychiatric hospitalizations one has in their lifetime significantly increases the odds of re-hospitalizations [5]. It is estimated that one in seven psychiatric illness patients are readmitted within one month [6].

Psychiatric diagnosis and other patient characteristics are associated with repeat psychiatric admissions. Lyons JS, et al. [7] described a greater likelihood of six-month readmission to psychiatric hospital for patients with poor self-care skills, greater symptom severity, and premorbid psychopathology. Others have observed a greater risk for readmission for patients who failed to comply with medication regimens [8] or reported less supportive family structures. Not surprisingly, patients who have undergone multiple admissions in the past or who experienced an earlier onset of symptoms are also at increased risk for re-hospitalization [9].

Many of the identified risk factors for psychiatric re-hospitalization involve the experience of significant distress resulting from psychopathology, family dysfunction, and generally poor coping skills. The cognitive behavioral process whereby persons identify, evaluate, and remedy stressful circumstances has been referred to as social problem solving. Deficient problem-solving skills are a risk factor for poor life functioning and mental disorders, including depression and schizophrenia [10-12].

Social problem solving is conceptualized as a flexible, multiplecomponent response that often functions at a covert level. Thus, the 
measurement and evaluation of social problem solving is challenging. Although self-reports of social problem solving have the benefit of being readily administered and scored, the measures are susceptible to response biases such as socially desirable responding [13]. In the context of psychiatric hospitalization, socially desirable responding might exaggerate or mask deficits in problem solving that contribute to frequent readmission. The Personal Problem Solving SystemRevised (PPSS-R) [14] was designed as an alternative to self-report assessments of problem-solving skills. The PPSS-R uses the Thematic Apperception Test [15] to evoke clinically relevant interpersonal themes and problem-solving responses. Rather than evaluate problem solving via self-report, the PPSS- $\mathrm{R}$ is a performance-based measure that codes responses using the social problem-solving model as a rubric [16].

This study evaluated whether social problem-solving skill at discharge could predict levels of psychiatric symptoms and rehospitalization at three and six months post discharge. That is, we hypothesized that social problem-solving skills would predict psychiatric symptoms and re-hospitalization after controlling for other identified psychiatric re-hospitalization risk factors. We also hypothesized that the performance-based measure of social problem solving (PPSS-R) [14] would result in a better prediction of rehospitalization than a self-report measure (SPSI-R) [17].

\section{Method}

\section{Participants}

Participants were solicited from three rural mid-western psychiatric hospitals. Each hospital was visited three times per week during the study period. Patients slated for discharge within 48 hours were asked to participate in a project evaluating factors that can predict rehospitalization. A total of 300 of the 566 available patients were asked to participate; the remaining 266 were discharged either sooner than anticipated, discharged despite medical advice, or unable to be seen by the primary investigator before discharge.

Fifty-five (18\%) of the potential subjects declined to participate, whereas 41 (14\%) patients were deemed ineligible due to legal incompetence primarily related to dementia. Thus, of the 300 patients contacted, $204(68 \%)$ met eligibility requirements and agreed to participate. There were no significant differences in the ratio of available to actual participants across the three hospitals, with the percentage of participants from each of the three hospitals mimicking the overall size of the psychiatric inpatient facilities $(45 \%, 44 \%$, and $10 \%)$. Over the course of the study participants could earn up to $\$ 10$; $\$ 5$ for completing the three-month follow up interview and an additional $\$ 5$ for completing the six-month follow up interview. Table 1 presents demographic information for the sample.

\section{Measures}

Demographic information was gathered from each patient's medical record and through a semi-structured interview. Demographic information included age, current diagnoses, follow up contact information, gender, number of prior psychiatric hospitalizations, post-discharge living arrangements, and race. During each followup contact, additional information was collected regarding current living arrangements, medication compliance, re-hospitalization, and utilization of services identified during discharge planning. In addition, five measures were used for assessment; three of which assessed symptoms, family emotional involvement, or life stress, while the remaining two measured problem solving skills.
Table 1: Characteristic Information for the Entire Sample.

\begin{tabular}{|c|c|}
\hline Variable & Value $(N=204)$ \\
\hline Demographics & $M(S D)$ \\
\hline \multirow[t]{2}{*}{ Age } & $40(13)$ \\
\hline & $\%$ \\
\hline Male & 49 \\
\hline Female & 51 \\
\hline Zero Prior Admissions & 26 \\
\hline 1-2 prior admissions & 34 \\
\hline 3 or more prior admissions & 38 \\
\hline \multicolumn{2}{|l|}{ Marital Status } \\
\hline Single & 36 \\
\hline Married & 32 \\
\hline Divorced/separated & 31 \\
\hline \multicolumn{2}{|l|}{ Race } \\
\hline Caucasian & 75 \\
\hline African American & 13 \\
\hline Native American & 7 \\
\hline Hispanic American & 5 \\
\hline \multicolumn{2}{|l|}{ Diagnosis } \\
\hline Substance Abuse & 22 \\
\hline Substance Use & 7 \\
\hline Depression & 54 \\
\hline Bipolar Disorder & 19 \\
\hline Psychotic Process & 16 \\
\hline Anxiety Disorder & 10 \\
\hline Adjustment Disorder & 8 \\
\hline Personality Disorder & 5 \\
\hline Comorbid Diagnosis & 32 \\
\hline \multicolumn{2}{|l|}{ Living Arrangements } \\
\hline Alone & 28 \\
\hline With Spouse/Relative & 52 \\
\hline With Friends & 9 \\
\hline Assisted Living & 1 \\
\hline Other & 7 \\
\hline \multicolumn{2}{|l|}{ Employment Status } \\
\hline Employed & 46 \\
\hline Unemployed & 54 \\
\hline
\end{tabular}

Behavior and Symptom Identification Scale (BASIS-32). The Behavior and Symptom Identification Scale (BASIS-32) [18], an empirically derived 32-item self-report measure of psychological symptoms, assessed psychiatric symptoms. The BASIS-32 possesses reasonable internal consistency, test-retest reliability, and constructs validity $[18,19]$.

Family Emotional Involvement and Criticism Scale (FEICS). The 14-item Family Emotional Involvement and Criticism Scale (FEICS) [20] assessed family emotional involvement and criticism. The FEICS possesses reasonable internal consistency, test-retest reliability, and construct validity $[18,19]$. 
Life Problem Inventory (LPI). The 11-item Life Problems Inventory (LPI) [21] assessed self-reported levels of stress across various broad domains: employment, health, living arrangements, recreation, and relationships. Participants used a 4-point scale to rate each item $(0=$ no distress to $4=$ severe distress). All analyses were conducted using a composite score derived from summing across items.

Social Problem-Solving Inventory-Revised (SPSI-R). The 25-item Social Problem-Solving Inventory-Revised, Short Form (SPSI-R) [17] assessed self-reported social problem-solving skills. The scale has demonstrated adequate internal consistency, test-retest reliability, and discriminate validity $[17,22]$.

Personal Problem Solving System-Revised (PPSS-R) the Thematic Apperception Test (TAT) [15] was used to elicit verbal responses that were subsequently coded using the Personal Problem Solving SystemRevised (PPSS-R) [14]. The PPSS-R uses cards from the TAT to evoke clinically relevant interpersonal themes that are evaluated based on 13 scoring criteria that are grouped into the four domains that mimic the [17] model (i.e., Story Design, Story Orientation, Story Solutions, and Story Resolution). The PPSS-R has demonstrated adequate internal consistency, test-retest reliability, and constructs validity, including among inpatient psychiatric patients [14]. Higher overall scores on the PPSS-R indicate better social problem-solving skills. An expert rater who was blind to participant information rated each of the typed, verbatim transcripts. Interrater agreement was assessed by having a second evaluator rate 5 percent of the verbatim transcript, which resulted in a correlation coefficient of 0.73 .

\section{Procedure}

Adults admitted to the selected inpatient units were screened for inclusion by the first author. Patients who met criteria for inclusion, that is, they were not developmentally and/or intellectually impaired, legally incompetent, nor actively psychotic, and who were slated for discharge within two days were asked to participate. Patients that agreed to participate completed the questionnaires described above. They also provided information on their age, gender, race, postdischarge living arrangements, and contact information for themselves and on someone they knew. They were asked to provide information about the problems they were currently experiencing, how they handled them, their psychiatric symptoms, and information about their relationships with others. In addition, patient charts were used to gather information on discharge planning, prior hospitalizations, diagnoses, medication information, and whether or not the patient had a history of substance abuse.

Three and six month post-discharge information on rehospitalization, self-reported medication compliance, living arrangements, and utilization of aftercare was gathered. Psychiatric symptomatology and number and severity of life stressors were also assessed. If the patient was unavailable, the above information was gathered from a caregiver (e.g., spouse or relative).

Of the 204 participants who completed the hospital portion of the study, three-month re-hospitalization data were gathered for 176 (86\%) of the participants. Three-month re-hospitalization and other follow up information was obtained directly from 151 (74\%) of the former patients and from 25 (12\%) caregivers in cases that the former patient could not be contacted. Three-month follow up information was missing for $28(14 \%)$ participants because neither they, nor a caregiver, could be reached. Attempts were made to contact these patients for the six-month follow up.
Six-month re-hospitalization and other follow up information were obtained for 159 (78\%) of the former patients; data was gathered directly from patients for 129 (63\%) of the participants and from 30 (15\%) caregivers because the former patient could not be contacted. Thus, all aspects of the six-month follow up were completed by $63 \%$ of the original sample at both times. Neither the former patient nor a caregiver could be contacted for 17 (8\%) participants during the six-month follow up-even though a three-month follow up had been completed. For the entire sample of 204 participants, no follow up information could be obtained for 27 (13\%) participants. During the three and six-month follow ups, two participants were reported by caregivers to have committed suicide.

Group differences: Several differences emerged when comparing the demographics of those who could not be followed up with, three-month follow up, and six-month follow up participants. Individuals unavailable for follow up, when compared with individuals in the three-month follow-up group, were more likely to report prior psychiatric hospitalizations, carry a personality disorder diagnosis, live alone prior to their psychiatric admission, be non-Caucasian, and older. Individuals in the group who were unable to be followed up with, when compared with individuals in the six-month follow-up group, were more likely to be separated or divorced, live alone prior to their psychiatric admission, be nonCaucasian, and be older. Table 2 provides further information about the group differences.

\section{Results}

An evaluation of the assumptions underlying normality suggested that PPSS-R data were skewed. The overall findings were similar using both normalized and non-transformed data; therefore, results using the original PPSS-R scores were used and are presented. The means and standard deviations of key variables grouped by readmission can be found in table 3 , and correlations among variables used to test the three-month and six-month post discharge predictions are contained in table 4. As apparent from the table, scores on the PPSS-R predicted re-hospitalization only at three months post discharge, whereas scores on the SPSI did not predict re-hospitalization at three or six months. Conversely, scores on the SPSI did predict self-reported psychiatric symptoms at three and six months, whereas scores on the PPSS-R did not predict selfreported psychiatric symptoms.

Table 2: Demographic Differences Between the No Follow Up Group and the 3 and 6 month follow Up Groups

\begin{tabular}{|l|c|c|c|c|c|c|}
\hline & \multicolumn{3}{|c|}{ Three Month } & \multicolumn{3}{c|}{ Six Month } \\
\hline Variable & \multicolumn{2}{|c|}{$\underline{\mathrm{t}}$ value } & $d f$ & $\underline{t}$ value & $d f$ \\
\hline Age & \multicolumn{2}{|c|}{$5.77^{* * *}$} & 169 & $5.26^{* * *}$ & 152 \\
\hline $\begin{array}{l}\text { Prior } \\
\text { hospitalizations }\end{array}$ & \multicolumn{2}{|c|}{$4.29 * * *$} & 167 & $4.34^{* * *}$ & 150 \\
\hline Variable & $\boldsymbol{\chi}^{2}$ & $\boldsymbol{d f}$ & $\boldsymbol{n}$ & $\boldsymbol{\chi}^{\mathbf{2}}$ & $\boldsymbol{d f}$ & $\boldsymbol{n}$ \\
\hline Race & $14.92^{* *}$ & 4 & 196 & $11.77^{*}$ & 4 & 197 \\
\hline $\begin{array}{l}\text { Prior living } \\
\text { situation }\end{array}$ & 9.3 & 8 & 155 & $10.32^{*}$ & 4 & 196 \\
\hline Marital status & $6.25^{*}$ & 2 & 196 & $7.09^{*}$ & 2 & 196 \\
\hline $\begin{array}{l}\text { Dx of personality } \\
\text { disorder }\end{array}$ & $5.8^{*}$ & 1 & 198 & 5.433 & 2 & 157 \\
\hline
\end{tabular}

Note: ${ }^{*}<<0.05, * * p<0.01, * * * p<0.001$ 
Table 3: Means and Standard Deviations of Key Variables Grouped by Readmission status and Follow up Status.

\begin{tabular}{|l|c|c|c|c|}
\hline & \multicolumn{2}{|c|}{ Rehospitalized } & \multicolumn{2}{c|}{ Not Rehospitalized } \\
\hline Variable & Three Month & Six Month & Three Month & Six Month \\
\hline PPSS-R & & & & \\
\hline M (SD) & $4.10(4.74)$ & $5.71(5.24)$ & $6.02(5.55)$ & $5.57(5.44)$ \\
\hline$n$ & 50 & 32 & 117 & 118 \\
\hline SPSI-R & & & & \\
\hline$M(S D)$ & $10.84(3.54)$ & $11.78(3.89)$ & $11.34(3.44)$ & $11.03(3.33)$ \\
\hline$n$ & 51 & 33 & 119 & 120 \\
\hline BASIS-32 & & & & \\
\hline$M(S D)$ & $1.04(0.70)$ & $1.10(0.60)$ & $0.75(0.65)$ & $0.67(0.67)$ \\
\hline$n$ & 33 & 18 & 108 & 105 \\
\hline LPI & & & & \\
\hline$M(S D)$ & $7.48(5.03)$ & $9.67(5.05)$ & $6.88(5.65)$ & $6.07(5.48)$ \\
\hline$n$ & 33 & 18 & 108 & 105 \\
\hline FEICS & & & & \\
\hline$M(S D)$ & $5.64(1.02)$ & $4.88(0.66)$ & $5.36(1.08)$ & $5.29(1.21)$ \\
\hline$n$ & 30 & 16 & 98 & 118 \\
\hline
\end{tabular}

Note: PPSS-R = Personal Problem Solving Inventory-Revised; SPSI-R= Social Problem Solving Inventory-Revised; BASIS-32=Behavior and Symptom Identification Scale-32; LPI=Life Problems Inventory; FEICS=Family Emotional Involvement and Criticism Scale.

\section{Problem Solving Skill and Re-hospitalization}

Participants who had poorer problem solving skill, as indicated by lower scores on the PPSS-R, at the time of their discharge were more likely to be readmitted to the hospital at three months. PPSS-R scores at the time of discharge were associated with re-hospitalization at three months, accounting for $4 \%$ of the variance, $\chi^{2}(1, N=167)=4.74$, $\mathrm{p}=0.03$; refer to table 5 . The SPSI was not significantly associated with re-hospitalization at three months and neither measure of problemsolving skill was associated with re-hospitalization at six months.

Hierarchical linear regression assessed whether problem-solving skill at the time of discharge, as measured by the PPSS-R, predicted re-hospitalization within three months of discharge after controlling age, number of prior hospitalizations, diagnosis of substance abuse, utilization of aftercare at three months, medication compliance at three months, and family emotional involvement and criticism at three months. As mentioned above, these variables have been associated with re-hospitalization in prior studies $[8,9]$. These control variables were entered as a block (step 1) followed by problem solving skill as measured by the PPSS-R (step 2). Entering the control variables as a block accounted for $11 \%$ of the variance associated with threemonth re-hospitalization. The subsequent entering of PPSS-R scores significantly increased the percent of variance associated with rehospitalization to $19 \%$; refer to table 6 . Thus, PPSS-R scores at the time of discharge were able to predict three month psychiatric rehospitalization even after controlling for relevant factors previously identified as related to psychiatric re-hospitalization.

\section{Problem Solving and Psychiatric Symptom Relapse}

Analyses were conducted to evaluate whether problem-solving skill would continue to predict reported psychiatric symptom level at three and six months after controlling for relevant risk factors. Because problem-solving skill as measured by the PPSS-R was not related to psychiatric symptom level at three or six months, only problem-solving skill as measured by the SPSI-R Short Form was included in analyses.
Table 4: Correlations among the Criterion and Predictor Variables.

\begin{tabular}{|l|c|c|c|c|c|c|c|}
\hline & Age & PPSS & SPSI & PH & DXSU & MC3M & TH3M \\
\hline Age & -- & & & & & & \\
\hline PPSS & -0.05 & -- & & & & & \\
\hline SPSI & $.19^{* *}$ & 0.01 & -- & & & & \\
\hline PH & $.17^{*}$ & 0.09 & 0.08 & -- & & & \\
\hline DXSU & $.16^{*}$ & 0.04 & 0.02 & 0.08 & -- & & \\
\hline MC3M & 0.02 & 0.07 & -0.08 & 0.04 & $-.28^{*}$ & -- & \\
\hline TH3M & 0.06 & $-.19^{*}$ & 0.09 & -0.07 & -0.02 & 0.11 & -- \\
\hline RH3M & 0.1 & $.16^{*}$ & 0.07 & -0.12 & 0.12 & -0.04 & -0.01 \\
\hline BASIS3M & $-.20^{*}$ & 0.06 & $-.33^{*}$ & 0.03 & -0.04 & 0.06 & $-.23^{*}$ \\
\hline LPI3M & $-.18^{*}$ & 0.09 & $-.27^{*}$ & 0.07 & -0.1 & 0.08 & $-.21^{*}$ \\
\hline FEICS3M & $-.29 *$ & 0.04 & $-.25^{*}$ & -0.03 & -0.13 & -0.04 & -0.13 \\
\hline MC6M & 0.11 & 0.18 & -0.08 & 0.08 & -0.16 & $.29 * *$ & -0.09 \\
\hline TH6M & -0.04 & -0.15 & 0.16 & -0.08 & -0.03 & $-.25 * *$ & 0.17 \\
\hline RH6M & 0 & -0.01 & -0.09 & $-.26 * *$ & $.19^{*}$ & -0.1 & 0 \\
\hline BASIS6M & -0.17 & 0.1 & $-.33^{* *}$ & 0.03 & 0.02 & 0.13 & -0.16 \\
\hline LPI6M & -0.15 & 0.09 & $-.26 * *$ & 0.05 & -0.12 & 0.11 & -0.1 \\
\hline FEICS6M & $-.20^{*}$ & 0.16 & $-.28^{* *}$ & -0.1 & 0.02 & 0.05 & -0.05 \\
\hline & RH3M & BASI3M & LPI3M & FEIC3M & MC6M & TH6M & \\
\hline RH3M & -- & & & & & & \\
\hline BASIS3M & $-.18^{*}$ & -- & & & & & \\
\hline LPI3M & -0.05 & $.77^{* *}$ & -- & & & & \\
\hline FEICS3M & -0.11 & $.21 *$ & $.24^{* *}$ & -- & & & \\
\hline MC6M & -0.04 & 0.16 & $.23^{*}$ & 0.07 & -- & & \\
\hline TH6M & $.20^{*}$ & $-.36^{* *}$ & $-.29^{* *}$ & -0.18 & $-.33^{* *}$ & -- & \\
\hline RH6M & $.20^{*}$ & $-.22^{*}$ & $-.22^{*}$ & 0 & -0.13 & 0.13 & \\
\hline BASIS6M & -0.02 & $.78^{* *}$ & $.57^{* *}$ & $.20^{*}$ & $.21^{*}$ & $-.40^{* *}$ & \\
\hline LPI6M & -0.02 & $.69^{* *}$ & $.70^{* *}$ & $.21^{*}$ & $.35^{* *}$ & $-.28^{* *}$ & \\
\hline FEICS6M & -0.09 & 0.17 & $.21^{*}$ & $.61^{* *}$ & 0.12 & $-.19^{*}$ & \\
\hline RH6M & RH6M & BASIS6M & LPI6M & FEICS6M & & & \\
\hline BASIS6M & $-.20^{*}$ & -- & & & & & \\
\hline LPI6M & $-.23^{*}$ & $.74^{* *}$ & -- & & & & \\
\hline FEICS6M & 0.13 & $.32^{* *}$ & $.31^{* *}$ & -- & & & \\
\hline
\end{tabular}

Note: $\mathrm{N}=198$; PPSS=Personal Problem Solving System-Revised total score; SPSI= Social Problem Solving Inventory-Revised Short Form total score; $\mathrm{PH}=$ Number of prior hospitalizations; DXSU=Diagnosis of Substance Abuse; MC3M=three month medication compliance; TH3M=Receipt of Therapy at Three Months; RH3M=Re-hospitalization Status at Three Months; BASIS3M=Behavior and Symptom Identification Scale-32 Average Score. LPI3M=Life Problems Inventory Total Score; FEICS3M=Family Emotional Involvement and Criticism Scale Total Score; MC6M=Six Month Medication Compliance; TH6M=Receipt of Therapy at Six Months; RH6M=Re-hospitalization Status between Three and Six Months; BASIS6M=Behavior and Symptom Identification Scale-32 Average Score; LPI6M=Life Problems Score Total Score; FEICS6M=Family Emotional Involvement and Criticism Scale Total Score; ${ }^{*} p<.05,{ }^{* *} p<.01$.

Self-reported problem solving skill was entered as the sole variable in linear regression analyses revealing that individuals with poorer problem solving skill at the time of discharge were more likely to report psychiatric symptom relapse at both the three, $\mathrm{F}(1,139)=16.98$, $\mathrm{p}<0.001$, and six month follow up, $\mathrm{F}(1,121)=14.53, \mathrm{p}<0.001$. At both three and six months, social problem solving accounted for approximately $11 \%$ of the variance; refer to table 7 . 
Table 5: Simple Regression of Problem Solving Skill on Three Month Hospital Readmission.

\begin{tabular}{|l|c|c|c|c|c|}
\hline & $\boldsymbol{R}^{2}$ & B & SE & $\operatorname{Exp}(\mathbf{B})$ & $\boldsymbol{p}$ \\
\hline PPSS-R & 0.04 & 0.73 & 0.04 & 1.08 & 0.03 \\
\hline
\end{tabular}

Note: $n=167$; PPSS-R=Personal Problem Solving System-Revised total score

Table 6: Hierarchical Regression of Control Variables and Problem Solving Skill on Three Month Hospital Readmission.

\begin{tabular}{|l|c|c|c|c|c|}
\hline & $\boldsymbol{R}^{2}$ & B & SE & Exp (B) & $\boldsymbol{p}$ \\
\hline Step 1 & 0.11 & & & & \\
\hline Age & & 0.04 & 0.02 & 1.04 & 0.04 \\
\hline Prior admissions & & -0.09 & 0.05 & 0.91 & 0.07 \\
\hline Substance abuse dx & & 0.04 & 0.65 & 1.04 & 0.96 \\
\hline Medication compliance & & -0.25 & 0.43 & 0.78 & 0.55 \\
\hline Receipt of therapy & & 0.18 & 0.51 & 1.2 & 0.72 \\
\hline FEICS3M & & -0.19 & 0.23 & 0.82 & 0.4 \\
\hline Step 2 & 0.19 & & & & \\
\hline PPSS-R & & 0.12 & 0.05 & 1.13 & 0.01 \\
\hline
\end{tabular}

Note: $N=117$; FEICS3M=three month Family Emotional Involvement and Criticism Scale Total Score; PPSS-R=Personal Problem Solving SystemRevised Total Score

Table 7: Simple Regression of Problem Solving Skill on Reported Psychiatric Symptoms.

\begin{tabular}{|l|c|c|c|c|c|}
\hline & B & $\boldsymbol{\beta}$ & $\boldsymbol{R}$ & $\boldsymbol{R}^{\mathbf{2}}$ & $\boldsymbol{p}$ \\
\hline SPSI-R & & & & & \\
\hline Three Month Follow Up & -0.06 & -0.33 & 0.33 & 0.11 & $<0.001$ \\
\hline Six Month Follow Up & -0.06 & -0.33 & 0.33 & 0.11 & $<0.001$ \\
\hline
\end{tabular}

Note: $N=140$ for three month data; $N=122$ for six month data; SPSI-R Short Form=Social Problem Solving Inventory-Revised Short Form

Hierarchical linear regression assessed whether self-reported problem-solving ability at the time of discharge predicted psychiatric symptoms three-months after discharge when controlling for age, number of prior hospitalizations, diagnosis of substance abuse, utilization of aftercare at three months, medication compliance at three months, and family emotional involvement and criticism at three months. Entering the control variables as a block accounted for $12 \%$ of the variance associated with psychiatric symptoms at three months. The subsequent entering of SPSI scores significantly increased the percent of variance associated with re-hospitalization to $20 \%$ $(\mathrm{p}=0.001)$. That is, SPSI scores at the time of discharge were significant in predicting psychiatric symptoms three months after discharge even after controlling for variables previously identified as related to psychiatric re-hospitalization; refer to table 8 .

At six months, the entering of control variables as a block in a hierarchical linear regression accounted for $26 \%$ of the variance associated with psychiatric symptoms six months after discharge. The subsequent entering of SPSI scores significantly increased the percent of variance associated with six month psychiatric symptoms to $29 \%$,
Table 8: Hierarchical Regression of Control Variables and Problem Solving Skill on Three Month Reported Psychiatric Symptoms.

\begin{tabular}{|l|c|c|c|c|c|c|}
\hline & $\boldsymbol{R}$ & $\boldsymbol{R}^{\mathbf{2}}$ & $\boldsymbol{B}$ & $\boldsymbol{\beta}$ & $\boldsymbol{S E}$ & $\boldsymbol{p}$ \\
\hline Step 1 & 0.35 & 0.12 & & & & \\
\hline Age & & & -0.003 & -0.07 & 0.01 & 0.47 \\
\hline Substance abuse dx & & & 0.16 & 0.09 & 0.17 & 0.35 \\
\hline Receipt of therapy & & & -0.3 & -0.21 & 0.12 & 0.02 \\
\hline No prior hospitalization & & & 0.01 & 0.08 & 0.01 & 0.35 \\
\hline Medication compliance & & & 0.11 & 0.09 & 0.11 & 0.3 \\
\hline FEICS & & & 0.04 & 0.07 & 0.06 & 0.43 \\
\hline Step 2 & 0.45 & 0.2 & & & & \\
\hline SPSI-R Total & & & -0.06 & -0.3 & 0.02 & 0.001 \\
\hline
\end{tabular}

Note: $\mathrm{N}=118$; FEICS=Family Emotional Involvement and Criticism Scale Total Score; SPSI-R Total=Social Problem Solving Inventory-Revised Short Form Total Score

$\mathrm{p}=0.04$. That is, SPSI scores at the time of discharge were significant in predicting psychiatric symptoms six months after discharge even after controlling for variables previously identified as related to psychiatric re-hospitalization; see table 9.

\section{Comparing Self Report and Performance Based Measure of Problem Solving}

To address the hypothesis that the PPSS-R would result in a better prediction of re-hospitalization and psychiatric symptom level than the SPSI-R, a comparison of predictive validity was conducted. This comparison indicated the two measures of problem solving yielded disparate results. Although the PPSS-R was related to three-month re-hospitalization $(r=0.16)$, it was not related to reported three or sixmonth psychiatric symptom level ( $\mathrm{r}=0.01$ and $\mathrm{r}=0.07$, respectively) or reported life stress ( $\mathrm{r}=0.05$ and $\mathrm{r}=0.04$, respectively). In contrast, the SPSI-R Short Form was related to three and six-month reported psychiatric symptom level ( $r=-0.33$ and $r=-0.27$, respectively), and life stress $(r=-0.30$ and $r=-0.26$, respectively), but was not associated with hospital readmission $(\mathrm{r}=0.14)$. Refer to table 4 to review these correlations.

\section{Discussion and Conclusion}

A primary goal of this study was to explore whether a psychiatric patient's ability to identify and solve problems in their life could buffer them from subsequent re-hospitalization and/or psychiatric relapse. Individuals with poor problem-solving skill were more likely to be readmitted to the hospital within three months following their index hospitalization, and they also reported higher psychiatric symptom levels at both three and six months after their index hospitalization. In addition, the influence of one's problem-solving skill remained after controlling for age, number of prior admissions, the presence of a diagnosis of substance abuse, utilization of aftercare, medication compliance, and family emotional involvement and criticism.

Interestingly, the two measures of problem solving, one a self-report measure and the other a performance-based measure, were orthogonal and had a differential influence on re-hospitalization and reported psychiatric symptom level. Problem-solving skill measured by the performance-based measure (PPSS-R) was related to three-month rehospitalization, but not reported psychiatric symptom level, whereas 
Table 9: Hierarchical Regression of Control Variables and Problem Solving Skill on Six Month Reported Psychiatric Symptoms.

\begin{tabular}{|l|c|c|c|c|c|c|}
\hline & $\boldsymbol{R}$ & $\boldsymbol{R}^{2}$ & $\boldsymbol{B}$ & $\boldsymbol{\beta}$ & $\boldsymbol{S E}$ & $\boldsymbol{p}$ \\
\hline Step 1 & 0.51 & 0.26 & & & & \\
\hline Age & & & -0.01 & -0.12 & 0.01 & 0.16 \\
\hline Substance abuse dx & & & 0.1 & 0.05 & 0.16 & 0.53 \\
\hline Receipt of therapy & & & -0.41 & -0.3 & 0.12 & 0.001 \\
\hline No prior hospitalization & & & -0.001 & 0.01 & 0.01 & 0.96 \\
\hline Medication compliance & & & 0.13 & 0.12 & 0.1 & 0.19 \\
\hline FEICS & & & 0.11 & 0.17 & 0.05 & 0.05 \\
\hline Step 2 & 0.54 & 0.29 & & & & \\
\hline SPSI-R Total & & & -0.04 & -0.18 & 0.02 & 0.04 \\
\hline
\end{tabular}

Note: $n=115$; FEICS=Family Emotional Involvement and Criticism Scale Total Score; SPSI-R Total=Social Problem Solving Inventory-Revised Short Form Total Score.

the self-report measure of problem-solving skill (SPSI-R) was related to three and six month reported psychiatric symptom level, but not re-hospitalization status. Given that the population was comprised of individuals with largely chronic and persistent mental illness, having a discrepancy between actual and reported problem-solving skill is not surprising. Some of the individuals who were readmitted to the hospital may have self-reported adequate problem-solving skills, but performed poorly when problem-solving skills were evaluated by the PPSS-R.

Another aspect of the study examined the relationship between life stress and other variables on hospital readmission and/or psychiatric relapse. Due to the problems of multi-collinearity between the measure for life stress and the measure for psychiatric symptom level, post hoc analyses were conducted to examine the influence of reported psychiatric symptom level on relapse and readmission. As hypothesized, reporting many psychiatric symptoms and high levels of life stress were both related to hospital readmission at six months. Correlations indicated that having numerous prior admissions and a substance abuse diagnosis were related to hospital readmission. Age was also related to hospital readmission wherein being young predicted readmission during the three-month follow up, and being older predicted readmission during the six-month follow up. Psychiatric symptom levels were consistently predicted by failure to utilize therapy services, being young and family emotional involvement and criticism (Tables 10-16).

These findings suggest that the assessment of social problemsolving skills can provide information that can be used to estimate the risk for future hospitalizations and inform the development of efficacious treatments designed to reduce psychiatric relapse. Problem-solving treatments are available for a variety of conditions that may require hospitalization including depression, schizophrenia and suicidal behavior [23]. Compared to other commonly used treatment modalities for depression, problem-solving therapies have the advantage of being less susceptible to client attrition [24].

The generalizability of the findings in this study was enhanced by having a good response rate during follow-ups, having a representative sample, and from gathering data from multiple psychiatric hospitals. The typical response rate reported in the literature for telephone follow ups is around $60 \%$. The three and six-month response rates for
Table 10: Simple Regression of Life Stress on Six Month Hospital Readmission.

\begin{tabular}{|l|c|c|c|c|c|}
\hline & $\boldsymbol{R}^{2}$ & B & SE & $\operatorname{Exp~(B)~}$ & $\boldsymbol{p}$ \\
\hline LPI6M & 0.09 & -0.11 & 0.04 & 0.89 & 0.01 \\
\hline
\end{tabular}

Note: N=123; LPI6M=Six Month Life Problems Inventory Total Score

Table 11: Hierarchical Regression of Control Variables and Reported Life Stress on Six Month Hospital Readmission.

\begin{tabular}{|l|c|c|c|c|c|}
\hline & $\boldsymbol{R}^{\mathbf{2}}$ & $\mathbf{B}$ & $\boldsymbol{S E}$ & $\operatorname{Exp}(\mathrm{B})$ & $\boldsymbol{p}$ \\
\hline Step 1 & 0.32 & & & & \\
\hline Age & & -0.08 & 0.03 & 0.92 & 0.02 \\
\hline Prior admissions & & -0.17 & 0.06 & 0.84 & 0.01 \\
\hline Substance abuse dx & & 2.32 & 0.83 & 10.19 & 0.01 \\
\hline Medication compliance & & 0.39 & 0.7 & 1.48 & 0.57 \\
\hline Receipt of therapy & & 0.77 & 0.76 & 2.17 & 0.31 \\
\hline FEICS6M & & 0.63 & 0.39 & 1.87 & 0.1 \\
\hline Step 2 & 0.4 & & & & \\
\hline LPI6M & & -0.19 & 0.08 & 0.83 & 0.02 \\
\hline
\end{tabular}

Note: $\mathrm{N}=116$; FEICS6M=six month Family Emotional Involvement and Criticism Scale Total Score; LPI6M=Six Month Life Problems Inventory Total Score

Table 12: Simple Regression of Life Stress on Reported Psychiatric Symptoms.

\begin{tabular}{|l|c|c|c|c|c|}
\hline & B & $\boldsymbol{\beta}$ & $\boldsymbol{R}$ & $\boldsymbol{R}^{\mathbf{2}}$ & $\boldsymbol{p}$ \\
\hline Three month LPI & 0.09 & 0.77 & 0.77 & 0.59 & $<0.001$ \\
\hline Six month LPI & 0.09 & 0.74 & 0.74 & 0.54 & $<0.001$ \\
\hline
\end{tabular}

Note: $\mathrm{N}=140$ for three month data; $\mathrm{N}=122$ for six month data; LPI=Life Problems Inventory Total Score

this study were higher, at 74 and $63 \%$, respectively. For a psychiatric population, these response rates are exceptionally high. Although in home follow up would have provided the maximal benefit, financial and time constraints precluded using this method.

As with any performance-based measure, the PPSS-R scores are based upon objective criteria that are evaluated by a rather and are susceptible to biases such as observer drift and disagreements between observers. The modest interrater reliability for the PPSS-R that was observed for this study calls for caution when interpreting results. Another limitation is the sample attrition during the study, especially for six-month analyses. Results based upon six-month data should be viewed with caution. The lack of reliability and validity information for the Life Problems Inventory (LPI) limits the confidence one can have in the findings. However, it appears face valid and is modeled after the Quality of Life Inventory (QOLI) [25], which has adequate reliability and validity.

Lastly, an assumption of this study was that individuals who were readmitted to the hospital symptomatically relapsed. However, it is likely that this assumption is false. Some individuals who are rehospitalized may be readmitted for reasons other than symptomatic relapse. In fact, such individuals may have adequate problem solving and readmission to the hospital is an effective problem-solving 
Table 13: Hierarchical Regression of Control Variables and Life Stress on Three Month Reported Psychiatric Symptoms.

\begin{tabular}{|l|c|c|c|c|c|c|}
\hline & $\boldsymbol{R}$ & $\boldsymbol{R}^{2}$ & $\mathbf{B}$ & $\boldsymbol{\beta}$ & $\boldsymbol{S E}$ & $\boldsymbol{p}$ \\
\hline Step 1 & 0.35 & 0.12 & & & & \\
\hline Age & & & -0.003 & -0.05 & 0.003 & 0.39 \\
\hline Substance abuse dx & & & 0.08 & 0.04 & 0.12 & 0.51 \\
\hline Receipt of therapy & & & -0.3 & -0.07 & 0.09 & 0.28 \\
\hline No Prior Hospitalization & & & -0.1 & 0.06 & 0.01 & 0.34 \\
\hline Medication compliance & & & 0.04 & 0.03 & 0.08 & 0.59 \\
\hline FEICS & & & 0.01 & 0.01 & 0.04 & 0.86 \\
\hline Step 2 & 0.77 & 0.59 & & & & \\
\hline LPI Total & & & 0.09 & 0.73 & 0.01 & $<.001$ \\
\hline
\end{tabular}

Note: $\mathrm{N}=118$; FEICS=Family Emotional Involvement and Criticism Scale total score; LPI=Life Problems Inventory total score.

Table 14: Hierarchical Regression of Control Variables and Life Stress on Six Month Reported Psychiatric Symptoms.

\begin{tabular}{|l|c|c|c|c|c|c|}
\hline & $\mathbf{R}$ & $\mathbf{R}^{2}$ & $\mathbf{B}$ & $\boldsymbol{\beta}$ & SE & $\boldsymbol{p}$ \\
\hline Step 1 & 0.51 & 0.26 & & & & \\
\hline Age & & & -0.003 & -0.06 & 0.003 & 0.31 \\
\hline $\begin{array}{l}\text { Substance Abuse } \\
\text { Diagnosis }\end{array}$ & & & 0.15 & 0.08 & 0.11 & 0.19 \\
\hline Receipt of Therapy & & & -0.25 & -0.19 & 0.09 & 0.004 \\
\hline $\begin{array}{l}\text { No Prior } \\
\text { Hospitalization }\end{array}$ & & & 0.01 & 0.04 & 0.01 & 0.48 \\
\hline $\begin{array}{l}\text { Medication } \\
\text { compliance }\end{array}$ & & & 0.04 & 0.07 & 0.04 & 0.26 \\
\hline FEICS & 0.8 & 0.64 & & & & \\
\hline Step 2 & & & 0.09 & 0.72 & 0.01 & $<.001$ \\
\hline LPI & & & -0.1 & -0.1 & 0.07 & 0.15 \\
\hline
\end{tabular}

Note: N=115; FEICS=Family Emotional Involvement and Criticism Scale Total Score; LPI=Life Problems Inventory Total Score

solution. The sensitivity of the study might be increased by separating participants into (a) those that were readmitted to the hospital, (b) those that were not readmitted but considered it, and (c) those that were not readmitted to the hospital and did not consider it. This might allow for additional associations to be identified between the criterion and predictor variables. In addition, an examination of the specific problem-solving stages could be used to determine if differences exist among readmitted or symptomatically relapsed patients within these specific stages. Such an analysis might allow for the development of interventions targeted at a particular problem-solving stage. The examination of the subscales of the other measures would allow for similar analyses and development of interventions.

\section{References}

1. Daniels BA, Kirkby KC, Hay DA, Mowry BJ, Jones IH (1998) Predictability of rehospitalisation over 5 years for schizophrenia, bipolar disorder and depression. Aust N Z J Psychiatry 32: 281-286.

2. McDermott KW, Elixhauser A, Sun R (2017) Trends in hospital inpatient stays in the United States, 2005-2014. Agency for Healthcare Research and Quality.
Table 15: Simple Regression of Reported Psychiatric Symptoms on Six Month Hospital Readmission.

\begin{tabular}{|l|c|c|c|c|c|}
\hline & $\boldsymbol{R}^{\mathbf{2}}$ & $\mathbf{B}$ & $\boldsymbol{S E}$ & $\operatorname{Exp}(\mathbf{B})$ & $\boldsymbol{p}$ \\
\hline 6MBASIS-32 & 0.07 & -0.79 & 0.36 & 0.45 & 0.02 \\
\hline
\end{tabular}

Note: $\mathrm{N}=123$; 6MBASIS-32=six month Behavior Symptom and Identification Scale-32 Average Score.

Table 16: Hierarchical Regression of Control Variables and Reported Psychiatric Symptoms on Six Month Hospital Readmission.

\begin{tabular}{|l|c|c|c|c|c|}
\hline & $\boldsymbol{R}^{\mathbf{2}}$ & B & SE & Exp (B) & $\boldsymbol{p}$ \\
\hline Step 1 & 0.32 & & & & \\
\hline Age & & -0.1 & 0.04 & 0.9 & 0.01 \\
\hline Prior admissions & & -0.17 & 0.06 & 0.85 & 0.01 \\
\hline Substance abuse dx & & 2.99 & 0.99 & 19.8 & $<.001$ \\
\hline Medication compliance & & 0.02 & 0.67 & 1.02 & 0.97 \\
\hline Receipt of therapy & & 0.26 & 0.84 & 1.29 & 0.76 \\
\hline FEICS6M & & 0.93 & 0.44 & 2.53 & 0.41 \\
\hline Step 2 & 0.47 & & & & \\
\hline 6MBASIS-32 & & -2.17 & 0.71 & 0.11 & 0.01 \\
\hline
\end{tabular}

Note: $\mathrm{N}=116$; FEICS6M=Family Emotional Involvement and Criticism Scale total score. 6MBASIS-32=Six Month Behavior and Symptom Identification Scale-32 Average Score

3. Perlman CM, Hirdes JP, Vigod S (2015) Psychiatric Rehospitalization: Development of a Person-Level Indicator for Care Planning and Quality Assurance. Prim Care Companion CNS Disord 17.

4. Haywood TW, Kravitz HM, Grossman LS, Cavanaugh JL, Davis JM, et al. (1995) Predicting the "revolving door" phenomenon among patients with schizophrenic, schizoaffective, and affective disorders. Am J Psychiatry 152: 856-861.

5. Zhao Y, Hoenig JM, Protacio A, Lim S, Norman CC (2020) Identification of risk factors for early psychiatric rehospitalization. Psychiatry Research 285.

6. Sprah L, Dernovsek M Z, Wahlbeck K, Haaramo P (2017) Psychiatric readmissions and their association with physical comorbidity: a systematic literature review. BMC psychiatry 17: 2.

7. Lyons JS, Kisiel CL, Dulcan M, Cohen R, Chesler P (1997) Crisis assessment and psychiatric hospitalization of children and adolescents in state custody. Journal of Child and Family Studies 6: 311-320.

8. Hunt GE, Bergen J, Bashir M (2002) Medication compliance and comorbid substance abuse in schizophrenia: Impact on community survival 4 years after a relapse. Schizophr Res 54: 253-264.

9. Langdon PE, Yagueez L, Brown J, Hope A (2001) Who walks through the 'revolving door' of a British psychiatric hospital? J Ment Health 10: 525-533.

10. Nezu AM (2004) Problem solving and behavior therapy revisited. Behavior Therapy 35: 1-33.

11. Nezu AM, Ronan GF (1988) Social problem solving as a moderator of stress-related depressive symptoms: A prospective analysis. J Couns Psychol 35: 134-138. 
12. Vaskinn A1, Sundet K, Friis S, Simonsen C, Birkenaes AB, et al (2008) Emotion perception and learning potential: Mediators between neurocognition and social problem-solving in schizophrenia? J Int Neuropsychol Soc 14: 279-288.

13. D'Zurilla TJ, Maydeu-Olivares (1995) Conceptual and methodological issues in social problem-solving assessment. Behavior Therapy 26: 409-432.

14. Ronan GF, Gibbs MS (2008) Scoring Manual for Personal Problem Solving System-Revised. In: Jenkins SR (eds) A Handbook of Clinical Scoring Systems for Thematic Apperceptive Techniques. Lawrence Erlbaum Associates, the University of Michigan 209-227.

15. Murray HA (1943) Thematic Apperception Test manual. Harvard University Press, Cambridge, MA.

16. D'Zurilla TJ, Goldfried MR (1971) Problem solving and behavior modification. J Abnorm Psychol 78: 107-126.

17. D'Zurilla TJ, Nezu AM, Maydeu-Olivares A (1996) Manual for the social problem-solving inventory-revised. North Tonawanda, NY: Multi-Health Systems.

18. Eisen SV, Wilcox M, Leff HS, Schaefer E, Culhane MA (1999) Assessing behavioral health outcomes in outpatient programs: Reliability and validity of the BASIS-32. J Behav Health Serv Res 26: 5-17.
19. Hoffman FL, Capelli K, Mastrianni X (1997) Measuring treatment outcome in adults and adolescents: reliability and validity of BASIS-32. J Ment Health Adm 24: 316-331.

20. Shields CG, Franks P, Harp JJ, Campbell TL, McDaniel SH (1994) Family Emotional Involvement and Criticism Scale (FEICS): II. Reliability and validity studies. Family Systems Medicine 12: 361-377.

21. Rathus JH, Miller AL (1995) Skills rating scale for adolescents.

22. Sadowski C, Moore LA, Kelley ML (1994) Psychometric properties of the social problem solving inventory (SPSI) with normal and emotionally disturbed adolescents. J Abnorm Child Psychol 22: 487500 .

23. Nezu AM, Nezu CM, Lombardo E (2004) Cognitive-behavioral case formulation and treatment design: A problem-solving approach. Springer Publishing Company.

24. Cuijpers P, van Straten A, Andersson G, van Oppen P (2008) Psychotherapy for depression in adults: A meta-analysis of comparative outcome studies. J Consult Clin Psychol 76: 909-922.

25. Frisch MB, Cornell J, Villanueva M, Retzlaff PJ (1992) Clinical validation of the quality of life inventory. A measure of life satisfaction for use in treatment planning and outcome assessment. Psychological Assessment 4: 92-101. 